\title{
REMOVAL OF DISSOLVED ORGANIC CARBON AND BROMIDE BY A HYBRID MIEX-ULTRAFILTRATION SYSTEM: INSIGHT INTO THE BEHAVIOUR OF ORGANIC FRACTIONS
}

\section{Oriol Gibert $^{\mathrm{a}, \mathrm{b}}$, Neus Pages ${ }^{\mathrm{a}}$, Xavier Bernat ${ }^{\mathrm{b}}$ and José Luis Cortina ${ }^{\mathrm{a}, \mathrm{b}}$}

\author{
${ }^{a}$ Chemical Engineering Dept., UPC-BarcelonaTECH, Av. Diagonal, 64708028 Barcelona, \\ Spain. \\ ${ }^{\mathrm{b}}$ Cetaqua, Water Technology Center, Ctra. Esplugues 75, 08940 Cornellà de Llobregat, Spain.
}

corresponding author: Oriol Gibert. Email: oriol.gibert@upc.edu

\begin{abstract}
Dissolved organic carbon (DOC) and bromide $\left(\mathrm{Br}^{-}\right)$are principal precursors in the formation of halogenated disinfection by-products resulting from chlorination of drinking water. Their effective removal from water represents, thus, one of the main challenges faced by drinking water treatment plants worldwide. The objective of this study was to evaluate the performance of a pilot-scale hybrid system based on the patented magnetic ion-exchange resin (MIEX) combined with ultrafiltration (UF) in the removal of $\mathrm{DOC}$ and $\mathrm{Br}^{-}$from water. Two different doses of MIEX ( $1 \mathrm{~mL} / \mathrm{L}$ and $3 \mathrm{~mL} / \mathrm{L})$ were applied and compared. Samples of feed water, UF permeate and tank solution were regularly collected to assess the system performance in terms of removal of DOC and $\mathrm{Br}^{-}$. DOC was characterised by high-performance size-exclusion chromatography (HPSEC) and 3D- fluorescence excitation-emission matrix (FEEM) to identify which organic fractions were preferentially removed by the MIEX/UF process. Results demonstrated that the hybrid MIEX/UF system was able to remove DOC and $\mathrm{Br}^{-}$from water.
\end{abstract}


The evolution and extent of these removals depended on the MIEX dose applied, with percentage removals clearly increasing when the MIEX dose was increased from $1 \mathrm{~mL} / \mathrm{L}$ to 3 $\mathrm{mL} / \mathrm{L}$. MIEX exhibited higher affinity toward DOC than toward Br-. Saturation of MIEX toward $\mathrm{Br}^{-}$was achieved short after the start of the experiment, while removal of DOC persisted until the end of the experiment. Fractionation of DOC by HPSEC indicated that the highest molecular weight fraction was mainly removed by size-exclusion by the UF membrane, while lower molecular weight fractions seemed to be better removed by ion-exchange on the MIEX resin. FEEM analysis revealed a poor affinity of MIEX toward microbial by-products, whereas fulvic and humic acid-like material were the most retained by MIEX.

Keywords: MIEX, ultrafiltration, dissolved organic carbon, bromide, HPSEC, FEEM.

\section{INTRODUCTION}

Dissolved organic carbon (DOC) and bromide $\left(\mathrm{Br}^{-}\right)$are principal precursors of halogenated disinfection by-products resulting from chlorination of drinking water [1]. The need for efficiently removing $\mathrm{DOC}$ and $\mathrm{Br}^{-}$has prompted drinking water treatment plants (DWTPs) to explore novel technical approaches that outperform conventional treatments (such as coagulation/flocculation, sand filtration or activated carbon adsorption) [2-4].

One of such approaches is the filtration by membranes. Microfiltration (MF) and ultrafiltration (UF) membranes can effectively remove particles, colloids and bacteria at low transmembrane pressures (not exceeding 2 bar), but are poorly effective at removing DOC and ions such as $\mathrm{Br}^{-}$due to their relatively large membrane pore sizes $[5,6]$. The removal of DOC and ions can be attained by using denser membranes such as nanofiltration (NF) and reverse osmosis (RO) membranes, but at expenses of applying high transmembrane pressures.

A significant drawback of the application of membrane technology, regardless the type of membrane used is membrane fouling with the subsequent reduction of the hydraulic 
permeability of the membrane [5]. DOC is acknowledged to be a main foulant even for MF and UF membranes, which can be fouled by organic substances through sieving effects and sorption on/in the membrane [6,7]. Thus, removal of DOC prior to a membrane step is usually necessary to alleviate membrane fouling.

Another approach to remove DOC is the application of an anion exchange resin (AER), taking advantage that most organic compounds in natural waters are in ionic form $[4,8]$. An AER that is receiving particular attention is the patented MIEX marketed by Orica Watercare. When in contact with it, negatively charged DOC is removed by exchanging with the mobile counterion on active sites on the MIEX surface (usually $\mathrm{Cl}^{-}$), resulting in a reduction in the DOC concentration and a small increase in $\mathrm{Cl}^{-}$concentration in the treated water $[9,10]$. MIEX differs from conventional AER by two unique properties: it is produced in the form of microsized beads $(\sim 180 \mu \mathrm{m}$, i.e. $2-5$ times smaller than conventional resins $)$ and it incorporates magnetic iron oxide within its core. The small size of the beads provides a high surface area that facilitates rapid exchange between $\mathrm{DOC}$ and $\mathrm{Cl}^{-}$[9-11], whereas the magnetic iron oxide within its core allows the beads to agglomerate into larger, fast-settling particles facilitating separation and recycling of the resin in a continuous process $[2,5,12]$. Due to these properties, MIEX resin is designed to be used either in a slurry contactor or in a fluidized bed, unlike larger, traditional AER commonly operated in packed beds [12]. In addition to DOC, MIEX has been reported to also exchange other anions from water such as $\mathrm{Br}^{-}[13]$.

The MIEX resin only removes part of DOC from water but does not remove turbidity, which needs to be removed (together with any resin beads that might be carried away from the system) by some form of treatment, e.g. by UF membranes. This combination gives rise to the hybrid MIEX/UF system, whereby water is first contacted with the MIEX resin and then the slurry MIEX/water is filtered through the UF membrane, which retains the loaded MIEX beads and turbidity. The premise of such an approach is that the hybrid system benefits from the enhanced removal of DOC by MIEX that would not be retained by UF alone [14], the removal of turbidity (and part of DOC) by UF not retained by MIEX alone and, according to some studies, the prevention of UF membrane fouling by DOC sorption onto the membrane [15]. 
Moreover, since fouling has recently been reported to be worsened by upstream oxidation processes (e.g. ozonation) commonly applied in DWTP [16], it is likely that MIEX would serve as a more desirable upstream treatment unit than oxidation.

Like with any treatment targeting DOC, characterisation of DOC by novel techniques such as high-performance size-exclusion chromatography (HPSEC) and fluorescence spectroscopy providing the 3-D fluorescence excitation-emission matrix (FEEM) has attracted the attention of researchers working with MIEX. Nevertheless, there are still some discrepancies on how physicochemical properties of DOC affects its removal by MIEX $[9,10]$. As outlined by Mergen and co-workers, "the current opinion with regard to the types or organic material preferentially removed by the [MIEX] resin is unclear" and, therefore, "there is a strong need for further research into the types of organic material that can be removed by the [MIEX] resin" [17].

There is relatively abundant research on MIEX for the removal of DOC from natural water. However, and although full-scale application of MIEX resin is intended for use in a continuous-flow process, most of the published studies have been carried out on a batch basis following either the single-loading procedure or, in an attempt to better mimic a continuousflow mode, multiple-loading procedure $[3,8,12,15]$. To get insight into the behaviour of DOC fractions, some of these studies have applied HPSEC and/or FEEM $[4,7,18,19]$. Some others have included $\mathrm{Br}^{-}$as target solute to be removed together with DOC, but often at relatively low concentrations of both $\mathrm{Br}^{-}$and $\mathrm{SO}_{4}{ }^{2-}$, which is a competitor for the MIEX exchangeable sites $[13,20,21]$. While these batch studies provide useful information on the capabilities of MIEX resin to remove DOC (and to a lesser degree $\mathrm{Br}^{-}$) their results cannot always be extrapolated to continuous-flow systems. Published studies based on continuous-flow systems can be found in the scientific literature $[11,12,22-24]$ and, of these, some have characterised DOC by means of HPSEC $[11,12,22]$ but to our knowledge none with FEEM. Finally, even less studies exist on hybrid systems based on MIEX/UF (or MF). Of these, some focus on the treatment of secondary- and tertiary- wastewater effluents that exhibit different organic composition and 
treatability from surface water [14,25], and fewer on surface water [2,5]. Again, some of these studies characterise DOC by HPSEC but not by FEEM.

The objective of this study was to evaluate the performance of a continuous-flow hybrid MIEX/UF system in the removal of DOC and $\mathrm{Br}^{-}$from sand-filtered surface water under two doses of MIEX (1 and $3 \mathrm{~mL} / \mathrm{L}$ ). DOC was characterised by HPSEC and FEEM to identify which organic fractions were preferentially removed by each of the two steps (MIEX and UF) of the hybrid system.

\section{MATERIALS AND METHODS}

\subsection{Feed water characteristics}

The water fed to the hybrid MIEX/UF system consisted of coagulated with $\mathrm{Al}_{2}\left(\mathrm{SO}_{4}\right)_{3}$ and then sand-filtered water from the DWTP of Sant Joan Despí (Barcelona, Spain). The average composition of this water is given in Table 1. As mentioned above DOC and $\mathrm{Br}^{-}$are of particular concern in many DWTP as they are main precursors of disinfectant by-products and, for this reason, were the target species in this study. Their concentrations were $3.0 \mathrm{mg} / \mathrm{L}$ and $0.62 \mathrm{mg} / \mathrm{L}$, respectively. The measured specific $\mathrm{UVA}_{254}$ absorbance (SUVA), which is defined as the ratio of $\mathrm{UVA}_{254}$ to $\mathrm{DOC}$, was $3.1 \mathrm{~L} /(\mathrm{mg} \cdot \mathrm{m})$. 
Table 1: Average composition of the feedwater to be treated by the hybrid MIEX/UF system

\begin{tabular}{lcc} 
Parameter & Units & Concentration \\
\hline $\mathrm{pH}$ & - & 7.6 \\
$\mathrm{DOC}$ & $\mathrm{mg} / \mathrm{L}$ & 3.0 \\
$\mathrm{Br}^{-}$ & $\mathrm{mg} / \mathrm{L}$ & 0.62 \\
suspended solids & $\mathrm{mg} / \mathrm{L}$ & 0.4 \\
turbidity & $\mathrm{NTU}$ & 1.76 \\
$\mathrm{alkalinity}^{-}$ & $\mathrm{mg} \mathrm{CaCO} / \mathrm{L}$ & 231 \\
$\mathrm{Cl}^{-}$ & $\mathrm{mg} / \mathrm{L}$ & 266 \\
$\mathrm{Na}^{+}$ & $\mathrm{mg} / \mathrm{L}$ & 155 \\
$\mathrm{~K}^{+}$ & $\mathrm{mg} / \mathrm{L}$ & 28 \\
$\mathrm{Ca}^{2+}$ & $\mathrm{mg} / \mathrm{L}$ & 104 \\
$\mathrm{Mg}^{2+}$ & $\mathrm{mg} / \mathrm{L}$ & 29 \\
$\mathrm{SO}_{4}^{2-}$ & $\mathrm{mg} / \mathrm{L}$ & 171 \\
$\mathrm{NO}_{3}^{-}$ & $\mathrm{mg} / \mathrm{L}$ & 15 \\
$\mathrm{I}^{-}$ & $\mathrm{mg} / \mathrm{L}$ & 0.06 \\
$\mathrm{SUVA}^{-}$ & $\mathrm{L} /(\mathrm{mg} \cdot \mathrm{m})$ & 3.1 \\
\hline & & \\
\hline
\end{tabular}

\subsection{Experimental set-up}

The pilot-scale hybrid MIEX/UF system, mounted on a skid with rollers for convenient mobility around the DWTP, was composed of a 40-L stirred tank containing the MIEX resin followed by a UF module (Fig 1). 


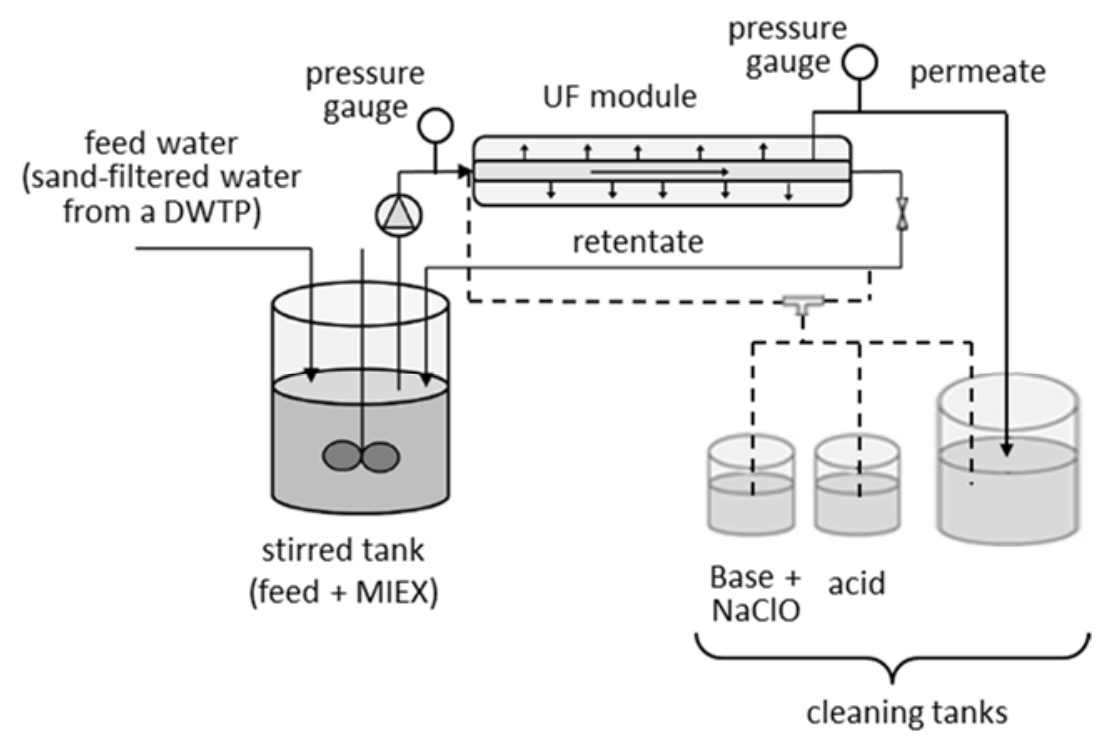

Figure 1. Schematic diagram of the pilot-scale hybrid MIEX/UF system.

The feed water was introduced at a flow rate of $10 \mathrm{~L} / \mathrm{h}$ into the tank where it entered in contact with the MIEX resin. Virgin MIEX resin (in the form of MIEX-Cl, i.e. in which $\mathrm{Cl}^{-}$was the mobile counter-ion) was received from Orica America as water slurry. Two different doses of MIEX $(1 \mathrm{~mL} / \mathrm{L}$ and $3 \mathrm{~mL} / \mathrm{L})$ were applied in the tank and compared. These MIEX doses corresponded to doses commonly used in practice for the treatment of drinking water $[9,19]$. Because the contact time provided by the stirred tank (ca. $4 \mathrm{~h}$ ) was much longer than the detention time specified by the MIEX manufacturer (ca. $30 \mathrm{~min}$ ) [12], the exchange within the tank was considered to be non time-controlled. The tank was continuously agitated to ensure uniformity of DOC and $\mathrm{Br}^{-}$concentration.

The water/resin slurry was then pumped at a flow rate of $30 \mathrm{~L} / \mathrm{h}$ into a UFC M5-type (X-Flow) UF module containing $100 \quad 1-\mathrm{m}$ long and 0.8 -mm-diameter hollow fibres corresponding to a filtration surface equal to $0.25 \mathrm{~m}^{2}$ (and a permeate flux of about $40 \mathrm{~L} /\left(\mathrm{m}^{2} \cdot \mathrm{h}\right.$ ). The UF polyethersulfone membranes (nominal MWCO of $100 \mathrm{kDa}$ ) operated in an inside-out cross-flow filtration mode. The retentate containing the MIEX beads was recirculated (approx. $20 \mathrm{~L} / \mathrm{h}$ ) into the feed tank while the permeate stream (approx. $10 \mathrm{~L} / \mathrm{h}$ ) was collected in a storage vessel. Because the MIEX resin was not continuously regenerated during the experiment, its ion 
exchange capacity (and the permeate quality) was expected to decrease with time. At approx. 2.0-2.5 hr intervals, 20-s hydraulic backwashes with permeate (occasionally enhanced with $\mathrm{NaOH}+\mathrm{NaClO}$ and $\mathrm{HCl}$ ) were applied to remove any foulant from the membrane. Appropriate combinations of valve positions allowed select the direction of the transmembrane flux during filtration cycles and backwashes episodes.

Samples of feed water, stirred tank solution and UF permeate were regularly collected to assess the system performance in terms of removal of $\mathrm{DOC}$ and $\mathrm{Br}^{-}$. For the experiment carried out with a MIEX dose of $3 \mathrm{~mL} / \mathrm{L}$, composite samples for the feed stream, tank solution and permeate (each made of 5 samples collected at different times) were analysed by HPSEC and FEEM to get insight into the DOC fractions behaviour.

\subsection{Analytical techniques}

Water samples for $\mathrm{DOC}$ and $\mathrm{Br}^{-}$analysis were filtered through pre-rinsed $0.45 \mu \mathrm{m}$ and $0.22 \mu \mathrm{m}$ syringe filters, respectively. DOC was measured using a TOC analyser (TOC Shimadzu Model V CPH) and $\mathrm{Br}^{-}$was determined by ion chromatography (Dionex ICS-1000).

Fractionation of DOC in $0.45 \mu \mathrm{m}$ filtered samples was performed by high-performance size-exclusion chromatography (HPSEC) and fluorescence spectroscopy.

HPSEC analysis was carried out using a Toyopearl TSK HW-50S column coupled to on-line ultraviolet, organic carbon and organic nitrogen detectors. Such system separates DOC fractions according to their hydrodynamic molecular size. Table 2 gives details on the time elution, molecular weight (MW) and constituents of each fraction [26]. 
Table 2: Chromatographic fractions of DOC as determined by the HPSEC technique.

\begin{tabular}{lcccc} 
DOC fraction & Abbreviation & Time (min) & MW (g/mol) & Constituents within fraction \\
\hline Biopolymers & BP & 31.0 & $>20000$ & Polysaccharides, proteins \\
$\begin{array}{lccc}\text { Humic substances } \\
\text { HS }\end{array}$ & 45.3 & $\approx 1000$ & Fulvic and humic acids \\
Building blocks & BB & 49.2 & $300-500$ & Breakdown products of humics \\
Low molecular weight neutrals & LMWN & 52.4 & $<350$ & Alcohols, aldehydes, ketones, \\
Low molecular weight acids & LMWA & 57.3 & $<350$ & sugars and amino acids \\
\hline
\end{tabular}

Three-dimensional fluorescence excitation-emission matrix (FEEM) spectra were collected on a LS55 Perkin Elmer fluorescence spectrophotometer using a $1 \mathrm{~cm}$ path length quartz cuvette. Fluorescence intensities were measured at excitation wavelengths $\left(\lambda_{\mathrm{ex}}\right)$ of 225 $515 \mathrm{~nm}$ in $10 \mathrm{~nm}$ increments and emission wavelengths $\left(\lambda_{\mathrm{em}}\right)$ of $230-650 \mathrm{~nm}$ in $10 \mathrm{~nm}$ increments, using a scan speed of $600 \mathrm{~nm} / \mathrm{s}$. The slit widths on excitation and emission modes were both set at $5 \mathrm{~nm}$. The photomultiplier tube voltage was set to $750 \mathrm{~V}$. MilliQ water was run as blank and its FEEM was subtracted from the sample FEEM in order to reduce the influence of Raman scattering. The fluorescence intensities were normalised by dividing them with the Raman-scatter peaks of the blank.

The FEEMs were divided into five regions (Region I to Region V) according to Chen [27]. Table 3 gives details on the excitation and emission ranges and constituents of each region [27].

Table 3: FEEM fractions of DOC as determined by FEEM spectroscopy.

\begin{tabular}{lccl} 
DOC region & Excitation range (nm) & Emission range (nm) & Component type \\
\hline Region I & $0-250$ & $180-320$ & Aromatic protein-like DOC-I \\
Region II & $0-250$ & $320-370$ & Aromatic protein-like DOC- II \\
Region III & $0-250$ & $370-570$ & Fulvic acid-like DOC \\
Region IV & $250-350$ & $180-370$ & Microbial by-product-like DOC \\
Region V & $250-420$ & $370-400$ & Humic acid-like DOC \\
\hline
\end{tabular}




\section{RESULTS AND DISCUSSION}

\subsection{DOC and $\mathrm{Br}^{-}$removal}

Feed water showed average DOC and $\mathrm{Br}^{-}$concentrations of $3.0 \mathrm{mg} / \mathrm{L}$ and $0.62 \mathrm{mg} / \mathrm{L}$, respectively, over the course of the study (Fig 2a and b). Results showed that the hybrid MIEX/UF system was able to remove DOC and $\mathrm{Br}^{-}$(Fig 2c and d). However, the evolution and extent of these removals depended on the MIEX dose.

a)
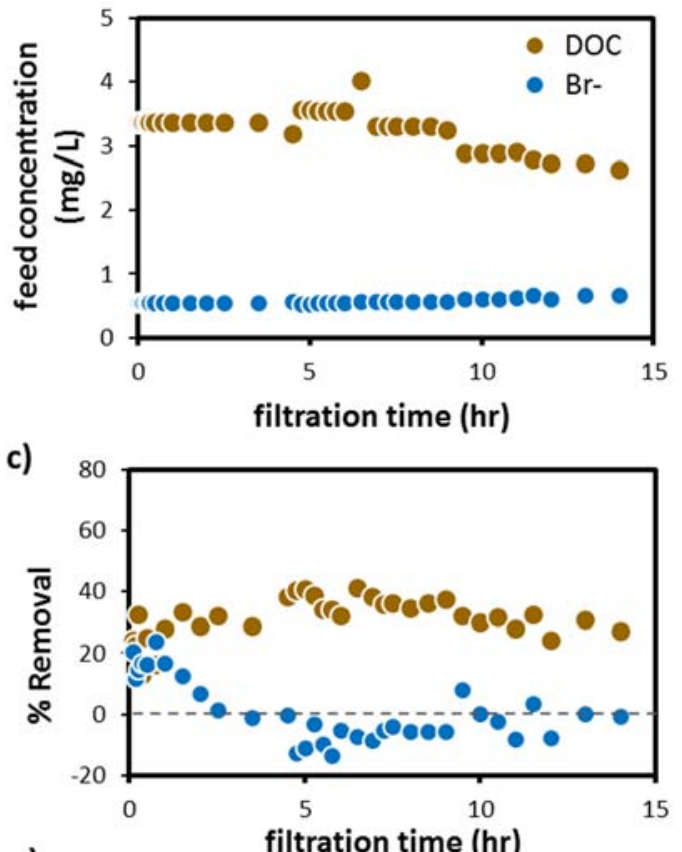

e)

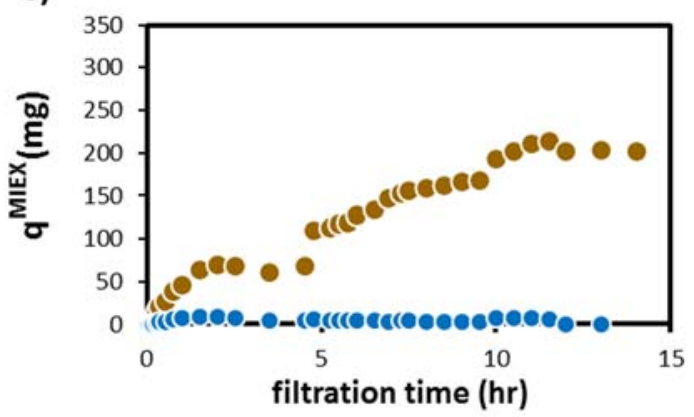

b)

MIEX dose: $3 \mathrm{~mL} / \mathrm{L}$

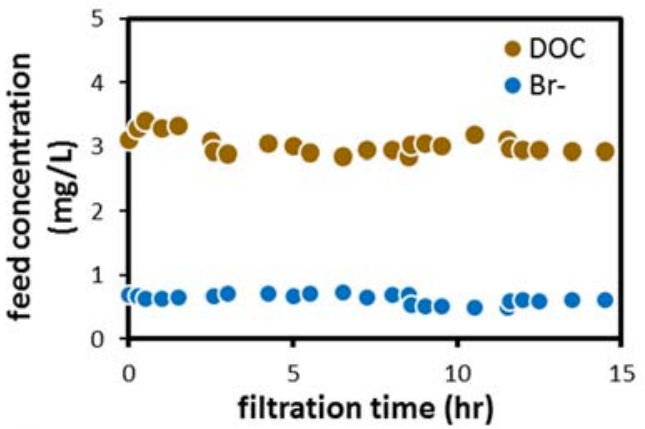

d)
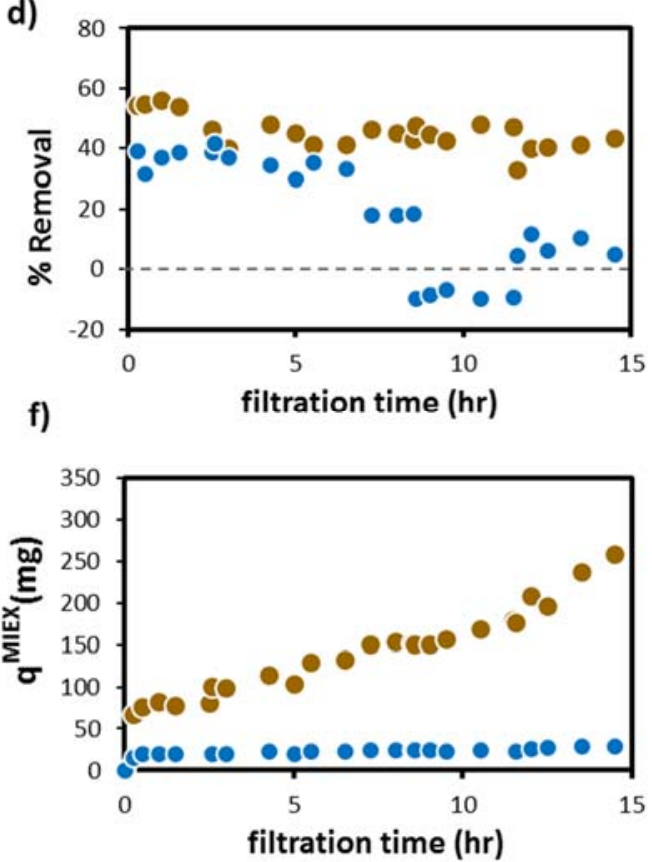

Figure 2: Evolution of a) inlet DOC and $\mathrm{Br}^{-}$concentration, b) $\mathrm{DOC}$ and $\mathrm{Br}^{-}$removal by the hybrid MIEX/UF system and c) DOC and $\mathrm{Br}^{-}$mass accumulated on the MIEX resin. 
At a MIEX dose of $1 \mathrm{~mL} / \mathrm{L}$, initial removals of $32 \%$ and $16 \%$ were observed for DOC and $\mathrm{Br}^{-}$, respectively (Fig 2c). The removal of DOC persisted over the whole duration of the experiment, while $\mathrm{Br}^{-}$removal ceased $3 \mathrm{hr}$ after the start of the experiment, suggesting saturation of MIEX toward $\mathrm{Br}^{-}$and that any fresh $\mathrm{Br}^{-}$entered into the system remained in water. Even a release of $\mathrm{Br}^{-}$from MIEX was observed after $5 \mathrm{hr}$ of experiment, probably due to a displacement of $\mathrm{Br}^{-}$by $\mathrm{DOC}$ and/other anions whose exchange onto the MIEX is more favourable. In fact, higher affinity of MIEX toward DOC (and other anions such as $\mathrm{SO}_{4}{ }^{2-}$ ) than toward $\mathrm{Br}$ - has been reported [20].

At a MIEX dose of $3 \mathrm{~mL} / \mathrm{L}$, the system achieved higher and more persistent DOC and $\mathrm{Br}^{-}$removals (Fig 2d). The initial DOC removal was 55\%, and it maintained stabilized at averaged $46 \%$ over the experiment, indicating that MIEX was able to decrease DOC concentration without reaching saturation yet. $\mathrm{Br}^{-}$was initially removed at a percentage of $37 \%$, but after approx. $8 \mathrm{hr}$ the removal decreased to zero indicating MIEX saturation toward $\mathrm{Br}^{-}$. Again, the release of $\mathrm{Br}^{-}$from MIEX at $12 \mathrm{hr}$ may be due to an increase of the concentration of competitive species (e.g. DOC or $\mathrm{SO}_{4}{ }^{2-}$ ) in feed water that can exchange with $\mathrm{Br}^{-}$, which is plausible as Llobregat river is characterised by a high (and sometimes fluctuating) content of ions. Competition between $\mathrm{Br}^{-}$and other anions clearly needs more research.

The removal of DOC and Br- was accompanied in both cases by a release of ions $\mathrm{Cl}^{-}$ (data no shown), confirming the anion exchange between aqueous DOC and $\mathrm{Br}$ - and MIEXphase $\mathrm{Cl}^{-}$.

It is important to note that these results demonstrated that the hybrid MIEX/UF system, regardless the MIEX dose applied, presented consistent DOC removals (32-46\%) much higher than UF alone $(<5 \%)$, as found in bench- and full-scale previous studies in the DWTP of Sant Joan Despí [6].

The results showed that the DOC removal clearly increased when the MIEX dose was increased from 1 to $3 \mathrm{~mL} / \mathrm{L}$. This expected finding is consistent with many published studies. In fact, the MIEX dose, together with the SUVA value, has been reported to critically affect DOC removal by MIEX. In general, higher MIEX doses and SUVA values lead to higher DOC 
removal $[10,12,15,21]$. The dependence of DOC removal upon MIEX dose and SUVA has been summarised and graphically illustrated by Boyer and Singer [12] (Figure 3). The DOC removal values obtained in this study have also been plotted in Figure 3, and it can be seen that they broadly match the general trend depicted by Boyer and Singer [12]. Little discrepancies were likely due to differences in system configuration (i.e. batch vs continuous operation modes), DOC physicochemical chacteristics (i.e. nature of organic fractions that constitute DOC), or concentration of other anions such as sulphate that may interfere with DOC removal.

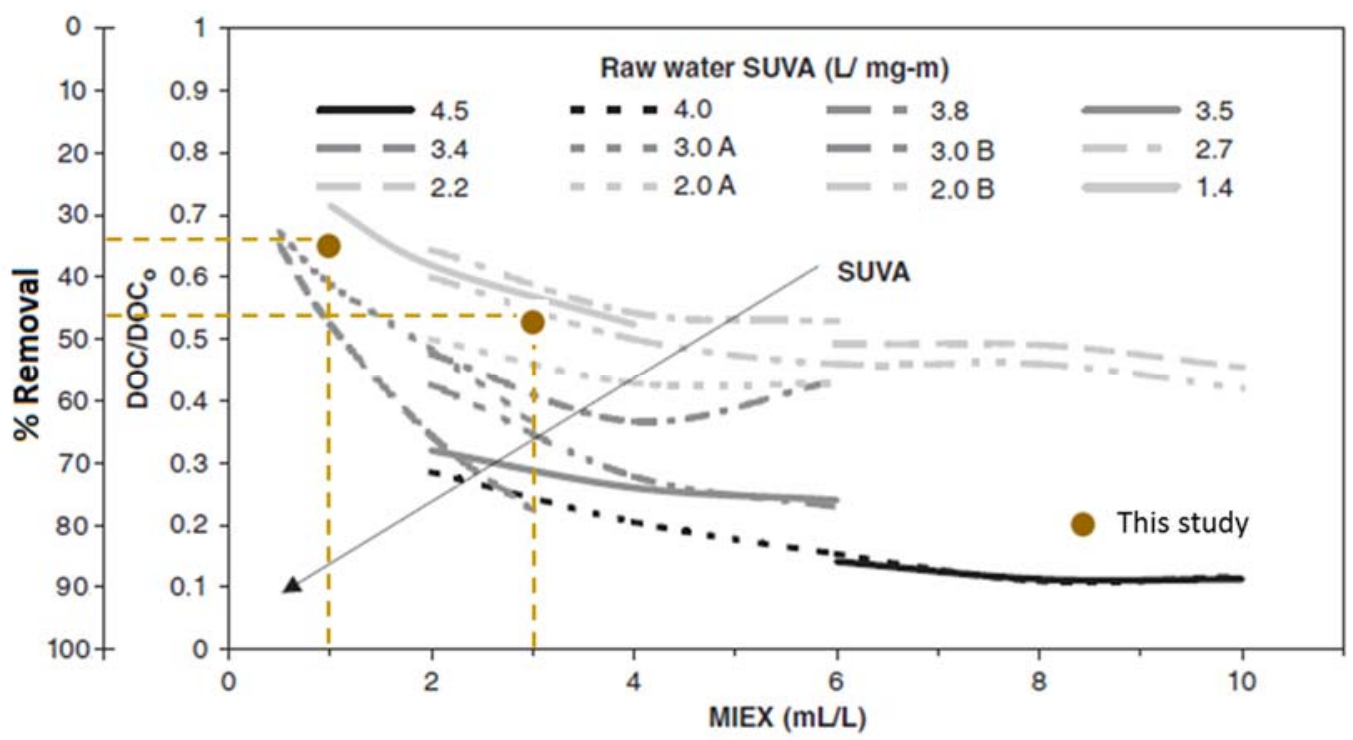

Figure 3: Dependence of the DOC removal upon the MIEX dose and the SUVA value of the treated water with the DOC removal values obtained in this study also plotted in the figure (modified from Boyer and Singer [17]).

Indeed, another parameter that has been found to strongly affect DOC removal is sulphate concentration. This is so because MIEX exhibits high selectivity for sulphate, and therefore elevated sulphate concentrations inhibit DOC removal due to the competitive nature of anion exchange. Figure 4 plots DOC removals by MIEX on a wide range of sulphate concentrations reported by published studies. The competition effect between sulphate and DOC for available active exchange sites on the MIEX resin is clearly noticeable. Again, the DOC removal values obtained in this study have also been plotted. It is worth noting that the 
tested sulphate concentrations by the previous studies were generally lower than the one tested here, with only one study focusing on the effect of sulphate at high concentrations [28]. The DOC removal percentages again matched the general trend, with slight discrepancies likely coming from differences in water qualities (e.g. SUVA values) or MIEX doses (see legend).

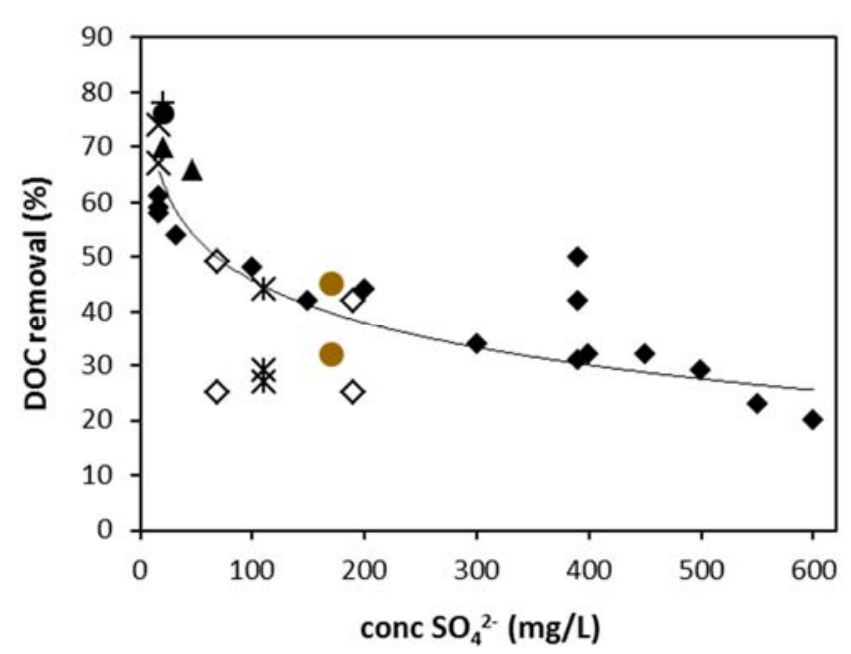

\begin{tabular}{|c|c|c|c|}
\hline & Reference & $\begin{array}{c}\text { SUVA } \\
\mathrm{L} /(\mathrm{mg} \cdot \mathrm{m})\end{array}$ & $\begin{array}{c}\text { MIEX dose } \\
\mathrm{mL} / \mathrm{L}\end{array}$ \\
\hline+ & [3] & 3.1 & 2 \\
\hline$\times$ & [4] & 3.6 & $1-5$ \\
\hline $\boldsymbol{\Delta}$ & [5] & $3.3-3.4$ & 5 \\
\hline & [7] & 2.5 & 8 \\
\hline * & [30] & $1.7-2.3$ & $1-8$ \\
\hline & [39] & $0.71-1.68$ & $5-10$ \\
\hline$\diamond$ & {$[40]$} & 2.2 & $5-10$ \\
\hline ? & This study & 3.0 & $1-3$ \\
\hline
\end{tabular}

Figure 4: Dependence of the DOC removal by MIEX upon the sulphate concentration.

Competition effects for available active exchange sites on the MIEX resin also applies for $\mathrm{Br}^{-}$removal. As shown in Figure 2, MIEX was found to be able to remove $\mathrm{Br}^{-}$, and the removal increased when the MIEX dose was increased from 1 to $3 \mathrm{~mL} / \mathrm{L}$. This finding, again, agrees with previous studies [19]. However, because $\mathrm{Br}^{-}$is commonly accompanied in natural waters by DOC and sulphate at very much higher concentrations, together with the fact that MIEX offer higher affinity toward DOC and sulphate than toward $\mathrm{Br}^{-}, \mathrm{Br}^{-}$removal by MIEX is often low $(<25 \%$ at background sulphate concentration of $10 \mathrm{mg} / \mathrm{L}$ or more) [12] or marginal $[13,28]$. In the present study, it is apparent that the relative high sulphate concentration (171 $\mathrm{mg} / \mathrm{L}$ ) strongly hinders the exchange of $\mathrm{Br}^{-}$on the exchangeable sites of the MIEX, provoking even a release of already exchanged/MIEX-phase $\mathrm{Br}^{-}$by DOC and/or $\mathrm{SO}_{4}{ }^{2-}$. 


\subsection{DOC and $\mathrm{Br}^{-}$masses loaded onto MIEX}

The total DOC amount entered and exited the hybrid system at any time $\left(\mathrm{q}_{\mathrm{DOC}}^{\mathrm{in,t}}\right.$ and $\mathrm{q}_{\text {DOC }}^{\text {out },}$, respectively $)$ can be calculated from the feed and permeate flow rates $\left(Q_{\text {feed }}\right.$ and $Q_{\text {permeate}}$, respectively) and their DOC concentrations $\left(c_{\text {DOC,feed }}^{\mathrm{t}}\right.$ and $\mathrm{c}_{\text {DOC,permeate }}^{\mathrm{t}}$, respectively) as follows:

$$
\begin{gathered}
\mathrm{q}_{\text {DOC }}^{\mathrm{in}, \mathrm{t}}=\mathrm{Q}_{\text {feed }} \cdot \int_{0}^{\mathrm{t}} \mathrm{c}_{\text {DOC,feed }}^{\mathrm{t}} \cdot \mathrm{dt} \\
\mathrm{q}_{\text {DOC }}^{\text {out } \mathrm{t}}=\mathrm{Q}_{\text {permeate }} \cdot \int_{0}^{\mathrm{t}} \mathrm{c}_{\text {DOC,permeate }}^{\mathrm{t}} \cdot \mathrm{dt}
\end{gathered}
$$

The difference between these amounts is the amount of DOC accumulated within the system at any time $\left(q_{D O C}^{\text {accum,t }}\right)$, either dissolved in the water $\left(q_{D O C}^{\text {diss, } t}\right)$ or loaded onto the MIEX resin $\left(\mathrm{q}_{\mathrm{DOC}}^{\mathrm{MIEX}, \mathrm{t}}\right)$. Because the solution in the tank was periodically analysed for DOC, the total amount of DOC dissolved at any time can be calculated:

$$
\mathrm{q}_{\mathrm{DOC}}^{\text {diss,t }}=\mathrm{V}_{\operatorname{tank}} \cdot \mathrm{c}_{\mathrm{DOC}, \operatorname{tank}}^{\mathrm{t}}
$$

where $V_{\text {tank }}$ is the volume of the tank and $c_{\text {DOC,tank }}^{t}$ the DOC concentration in the tank at any time. By substracting this amount from $\mathrm{q}_{\mathrm{DOC}}^{\text {accum,t }}$, the DOC loaded onto the resin can be calculated:

$$
\mathrm{q}_{\mathrm{DOC}}^{\text {MIEX,t }}=\mathrm{q}_{\text {DOC }}^{\text {accum,t }}-\mathrm{q}_{\mathrm{DOC}}^{\text {diss,t }}
$$

Similar calculations can be done for quantifying the mass of Br- loaded onto the resin at any time $\left(\mathrm{q}_{\mathrm{Br}}^{\text {MIEX,t }}\right)$. Figure $2 \mathrm{e}$ and $2 \mathrm{f}$ shows $\mathrm{q}_{\mathrm{DOC}}^{\text {MIEX,t }}$ and $\mathrm{q}_{\mathrm{Br}}^{\text {MIEX,t }}$ calculated through the massbalance described above for both MIEX doses. 
The figure shows that $\mathrm{q}_{\mathrm{DOC}}^{\mathrm{MIEX}, \mathrm{t}}$ kept increasing with time for both doses, indicating that the MIEX resin was not saturated yet and still offered some capacity of retaining DOC. This was consistent with the continuous removal of DOC (Figure $2 \mathrm{c}$ and $2 \mathrm{~d}$ ). $\mathrm{q}_{\mathrm{DOC}}^{\mathrm{MIEX}, \mathrm{t}}$ by the end of the experiment was ca. $202 \mathrm{mg}$ and $258 \mathrm{mg}$ DOC for doses $1 \mathrm{~mL} / \mathrm{L}$ and $3 \mathrm{~mL} / \mathrm{L}$, respectively. In

contrast $\mathrm{q}_{\mathrm{Br}}^{\mathrm{MIEX}, \mathrm{t}}$, which was much lower than $\mathrm{q}_{\mathrm{DOC}}^{\mathrm{MIEX}, \mathrm{t}}$, kept invariable at the late stage of the experiment (at around 4 and $26 \mathrm{mg}$ for doses $1 \mathrm{~mL} / \mathrm{L}$ and $3 \mathrm{~mL} / \mathrm{L}$ ) indicating that MIEX was saturated toward $\mathrm{Br}^{-}$.

Very few data on DOC masses loaded on MIEX exist in the literature. The values obtained in this study were in the same order of magnitude of that reported by Nguyen et al. [24] from batch tests with synthetic water in contact with a dose of MIEX of $1 \mathrm{~mL} / \mathrm{L}$ $\left(\mathrm{q}_{\mathrm{DOC}}^{\mathrm{MIEX}}=4.1 \mathrm{mg} / \mathrm{mL}\right)$.

\subsection{DOC characterisation using HPSEC}

Figure 2 showed that, under both MIEX doses, DOC was removed since the very beginning of the experiment, but also that there was always a fraction of DOC that was not exchanged onto MIEX and permeated the UF membranes.

Comparison of HPSEC chromatograms between feed water and UF permeate (Fig 5a and b) showed that the whole hybrid system basically removed low-MW fractions (reduced peaks for BB and LMWN) and high-MW fractions (BP). On the other hand, mid-MW fractions (HS) were less removed. Comparison against the chromatogram for the solution in the tank with MIEX suggested that the removal mechanisms for these fractions were different.

The removal mechanism for $\mathrm{BP}$ seemed to be not via ion-exchange onto MIEX (BP remained in solution when in contact with MIEX as highlighted by the large peak in Fig 5c) but via size exclusion by the UF membrane. This is in accordance with previous works reporting poor removals of high MW compounds by MIEX [12] but moderate or high removals of high MW compounds by UF [6,7]. The poor removal by MIEX of high MW compounds is likely due 
to the fact that these compounds (mainly polysaccharides, proteins - see Table 2) tend to be uncharged and are therefore unlikely to have a strong affinity for exchange onto an anion exchange resin such as MIEX [17,22]. The moderate or high removals of high MW compounds by UF is in agreement with the results reported by Humbert et al. [7], who found that foulants retained on a UF membrane receiving a MIEX-treated water "mainly corresponded to high MW DOM of microbial origins (i.e. mixture of polysaccharides, amino sugars and proteins).

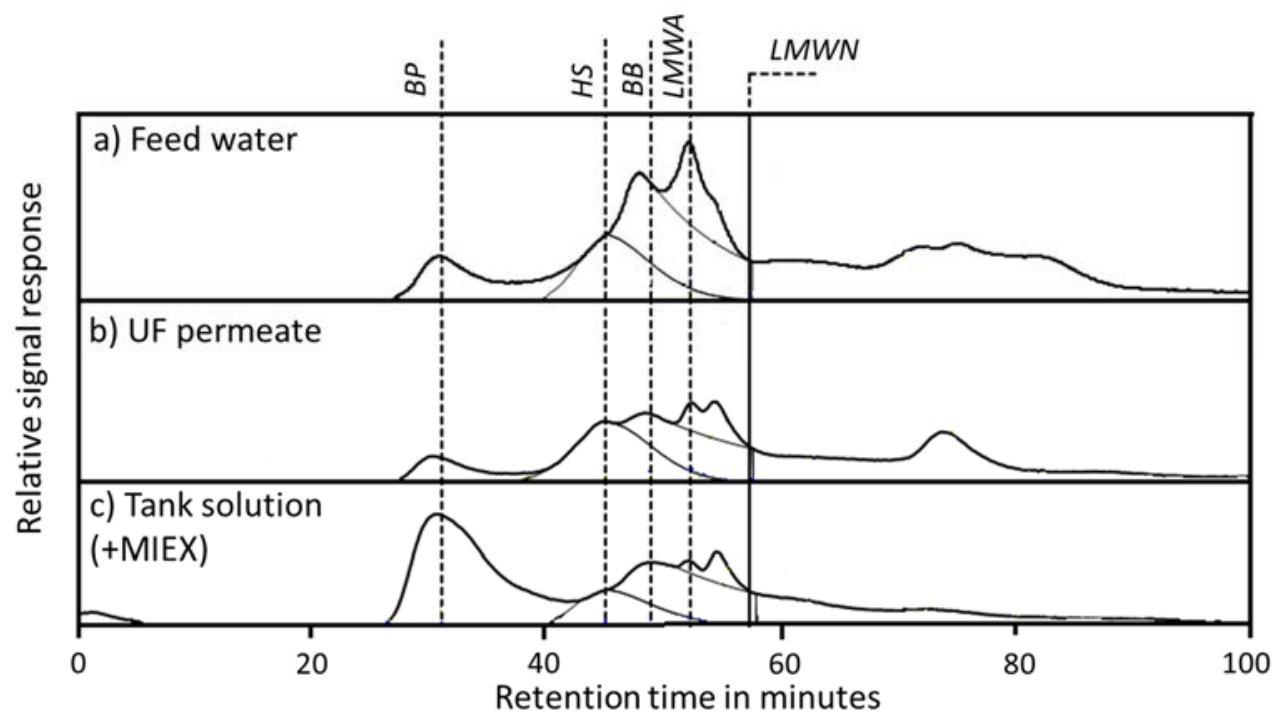

Figure 5: HPSEC chromatograms for feed water, UF permeate and tank solution.

Contrarily to BP, the lower MW fractions BB and LMWA seemed to be better removed by ion-exchange onto MIEX, as highlighted by their decreased peaks in the tank solution (Fig 5c), but not by the UF membrane (little differences in their peaks were observed between the tank solution and the UF permeate). This finding agreed with the preferential removal of low MW fractions by MIEX $[5,7,12,14]$ attributed to the fact that low MW compounds are more enriched in negatively charged species such as carboxylic acids [22]. The poor retention of low MW compounds by UF membranes has also been widely reported in the literature [6,7].

Although the pattern on preference of MIEX toward low-MW compounds observed in this study were consistent with many previous published studies, opposite trends have also been reported. For instance, Singer et al. [23] observed that "removal increased in effectiveness as the 
nominal molecular weight of the NOM increased" and attributed this pattern to differences in hydrophobicity of the organic fractions, since "larger MW DOC species corresponded to hydrophobic organic acids $[\ldots]$ whereas the smaller molecular weight fractions was associated with hydrophilic species". Focusing on a MW range of 700-4000 Da, Phetrak et al. [18] reported that "aromatic DOM greater than 1600 Da was completely removed by MIEX [...] by the fact that the macroporosity, small resin size and iron oxide content of MIEX provided greater DOM accessibility and more solid-liquid interfaces, resulting in a more rapid removal of aromatic DOM greater 1600 Da" while "aromatic DOM smaller than 1000 Da remained after [MIEX] treatment". As it has been highlighted "there is [still] a strong need for further research into the types of organic material that can be removed by the [MIEX] resin" [17].

\subsection{DOC characterisation using FEEM}

The FEEM spectra of feed water, UF permeate and tank solution (+MIEX) are depicted in Figure 6 showing labelled areas for each region (from I to VI) described in the Materials and Methods section. Note that the scale is different for the UF permeate. Table 4 provides the values of the fluorescence intensity of each peak (in arbitrary fluorescence units), which give estimates of the relative concentrations of each component.

Table 4: Values of the fluorescence intensity of each peak (in arbitrary fluorescence units) for the feed water, UF permeate and the tank solution (+MIEX).

Region Component type

\begin{tabular}{llccc}
\hline & & Feed water & UF permeate & Tank solution (+MIEX) \\
\hline II & Aromatic protein-like DOC-II & 15.3 & 4.7 & 11.1 \\
III & Fulvic acid-like DOC & 6.1 & 1.7 & 2.5 \\
IV & Microbial by-product-like DOC & 4.6 & 2.0 & 4.8 \\
V & Humic acid-like DOC & 4.3 & 1.1 & 2.4 \\
\hline
\end{tabular}


Comparison of FEEMs between feed water (Fig 6a) and UF permeate (Fig 6b) reflected a substantial reduction of all four fluorescence peaks across the whole hybrid system. The reduction percentages were: $69 \%$ (for region II), $72 \%$ (for region III), $57 \%$ (for region IV), $74 \%$ (for region V). Humic and fulvic acid-like substances were, thus, the classes of organic substances most retained by the hybrid system, closely followed by proteinaceous material, while microbial by-products were less retained.
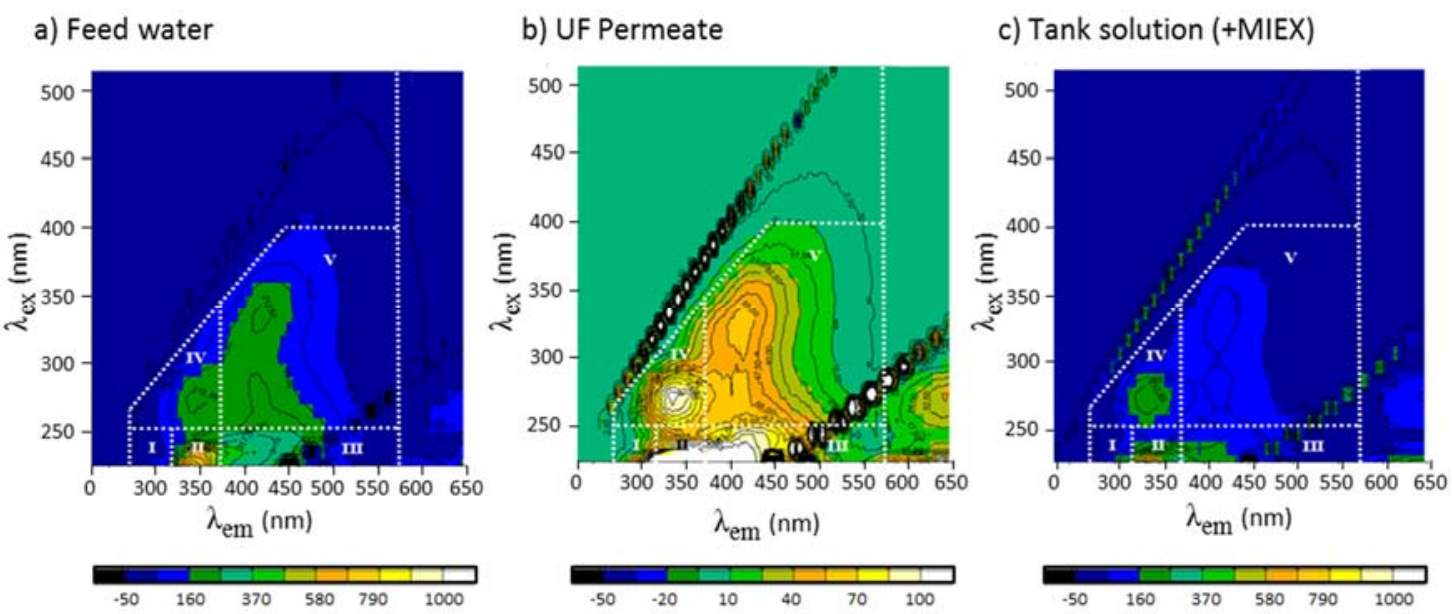

Figure 6: FEEM contour plots for a) feed water, b) UF permeate and c) tank solution (+MIEX) (note that the scale is different for the UF permeate).

Contrasting HPSEC and FEEM techniques, it can be observed that they showed similarities and differences. For instance, moderate retention of microbial by-products would be in accordance with the moderate removal of fraction BP (associated to microbial by-products) shown in HPSEC chromatograms of the same samples (Figure 5). However, an apparent discrepancy between both techniques is that the fraction termed "humic substances" (HS) in HPSEC was poorly removed by the hybrid MIEX/UF system while fluorescence peak in region V in FEEM (associated to "humic acid-like DOC) was appreciably reduced. It must be stressed that concordance between fractions from HPSEC and regions from FEEM must be regarded with caution for at least three reasons: first, characterisations based on MW and fluorescence do not lead to unequivocally corresponding fractions; second, limits between MW for the different HPSEC fractions and between $\lambda_{\mathrm{em}} / \lambda_{\mathrm{ex}}$ for the different FEEM regions are not precisely defined; 
and third, it is unknown which fraction of the total DOC gives response to fluorescence analysis. Difficulties in comparing HPSEC fractions and FEEM regions are also reported by Henderson et al. [30], who reported that "proteinaceous material [...] might have a range of sizes from 20 to $150 \mathrm{kDa}[\ldots]$ or might be present as a LMW amino acid". How HPSEC and FEEM complement each other arises as a field of research.

Comparison of FEEMs between feed water (Fig 6a) and tank solution (+MIEX) (Fig 6c) showed lowered fluorescence intensity peaks by $28 \%$ (for region II), $59 \%$ (for region III), and $44 \%$ (for region $\mathrm{V}$ ) revealing a preference of MIEX toward fulvic and humic acid-like material. The intensity of peak in region IV in the tank solution was even higher $(+4 \%)$ than that in feed solution, indicating a poor affinity of MIEX toward microbial by-products. This, together with the relatively high retention of microbial by-products by UF, resulted in their accumulation within the tank. This finding is consistent with the HPSEC chromatograms shown in Figure 5, whereby fraction BP appeared to be accumulated into the tank.

Because HPSEC defines DOC fractions according to their hydrodynamic molecular size while FEEM according to their fluorescence properties, it can then be concluded that MIEX showed more affinity toward humic and fulvic substances and their breakdown products, in particular those with low MW and exhibiting fluorescence. On the other hand, the UF membrane seemed to preferentially remove organic substances with high MW and again exhibiting fluorescence.

Findings on NOM removal by MIEX are in partial agreement with published studies on treatment of surface water by MIEX (under similar doses) monitored by FEEM with the spectra division proposed by Chen et al. [27]. It must be noted that comparison between studies may be difficult because the position of observed peaks within a region do not always coincide exactly, indicating that different organic matter might be compared between studies. In agreement with the present study, Phetrak et al. [18] also observed, with a MIEX dose of $2 \mathrm{~mL} / \mathrm{L}$, greater reductions in peak intensities for regions III and V (51-77\%) than for regions I, II and IV $(<30 \%)$. They attributed the higher removal of regions III and V to the fact that fulvic and humic-like compounds are negatively charged at the current $\mathrm{pH}$ and thus can be easily removed 
by ion exchange mechanism. Apell and Boyer [4] also reported a lowered peak (by 76\%) for region $\mathrm{V}$ and for region IV when it appeared in some samples, but any other peak is reported. In contrast, $\mathrm{Xu}$ et al. [19], with a MIEX dose of $1 \mathrm{~mL} / \mathrm{L}$, did not find higher reductions of the peaks corresponding to fulvic and humic substances. These sparse results in literature sources make evident that more research on DOC characterisation, and in particular on complementary between different characterisation techniques, in MIEX-assisted treatments is needed.

\section{CONCLUSIONS}

This study demonstrated that the hybrid MIEX/UF system was able to remove DOC and $\mathrm{Br}^{-}$, with percentage removals clearly higher when the MIEX dose was increased from $1 \mathrm{~mL} / \mathrm{L}$ to $3 \mathrm{~mL} / \mathrm{L}$. MIEX exhibited higher affinity toward DOC than toward $\mathrm{Br}^{-}$, with initial DOC removals of $32 \%$ and $55 \%$ for both MIEX doses, against $16 \%$ and $37 \%$ for Br. Saturation of MIEX toward $\mathrm{Br}^{-}$was achieved short after the start of the experiment, while removal of DOC persisted until the end of the experiment. The mass of DOC loaded onto the MIEX resin $\left(q_{\text {DOC }}^{\text {MIEX,t}}\right.$ ) by the end of the experiment was ca. $202 \mathrm{mg}$ and $258 \mathrm{mg}$ DOC for doses $1 \mathrm{~mL} / \mathrm{L}$ and

$3 \mathrm{~mL} / \mathrm{L}$, respectively, while $\mathrm{q}_{\mathrm{Br}}^{\mathrm{MIEX}, \mathrm{t}}$ was around 4 and $26 \mathrm{mg}$ for doses $1 \mathrm{~mL} / \mathrm{L}$ and $3 \mathrm{~mL} / \mathrm{L}$, respectively. The removal mechanism by the hybrid system MIEX/UF was different for each DOC fraction as analysed by HPSEC. The high MW (and poorly negatively charged) fraction BP was mainly removed by size exclusion by the UF membrane, while lower MW fractions (more enriched in negatively charged species) such as BB and LMWA were better removed by ion-exchange onto MIEX. FEEM analysis revealed a poor affinity of MIEX toward microbial by-products (which can be associated with BP), which is consistent with HPSEC results, whereas fulvic and humic acid-like material were the most retained by MIEX. It can then be concluded that MIEX showed more affinity toward humic and fulvic substances and their breakdown products, in particular those with low MW and exhibiting fluorescence. On the other 
hand, the UF membrane seemed to preferentially remove organic substances with high MW and again exhibiting fluorescence. The hybrid MIEX/UF system removed DOC (by 32-46\%) more efficiently than UF alone $(<5 \%)$, demonstrating the benefits of combining ion-exchange and UF processes. The reason of this lies in the fact that a wider spectrum of organic compounds can be removed by the sum of both processes than by one alone. Finally, since fouling has recently been reported to be worsened by upstream oxidation processes (e.g. ozonation) commonly applied in DWTP [16], it is likely that MIEX would serve as a more desirable upstream treatment unit than oxidation.

\section{LIST OF SYMBOLS AND ACRONYMS}

AER: anion exchange resin

BB: building blocks

BP: biopolymers

$c_{\text {DOC,feed }}^{t}$ : DOC concentration in feed at any time $(\mathrm{mg} / \mathrm{L})$

$c_{\text {DOC,permeate }}^{t}:$ DOC concentration in permeate at any time $(\mathrm{mg} / \mathrm{L})$

$\mathrm{c}_{\mathrm{DOC}, \operatorname{tank}}^{\mathrm{t}}$ : DOC concentration in the tank at any time $(\mathrm{mg} / \mathrm{L})$

DOC: dissolved organic carbon

DWTP: drinking water treatment plant

FEEM: fluorescence excitation emission matrix

HPSEC: high-performance size-exclusion chromatography

HS: humic substances

LMWA: low molecular weight acids

LMWN: low molecular weight neutrals

MF: microfiltration

MIEX: magnetic ion exchange 
MW: molecular weight

NF: nanofiltration

$\mathrm{Q}_{\text {feed }}$ : feed flow rate $(\mathrm{L} / \mathrm{s})$

$\mathrm{Q}_{\text {permeate }}$ : permeate flow rate $(\mathrm{L} / \mathrm{s})$

$\mathrm{q}_{\text {DOC }}^{\text {in,t }}:$ total DOC amount entered the hybrid system at any time $(\mathrm{mg})$

$\mathrm{q}_{\text {DOC }}^{\text {out,t }}$ : total DOC amount exited the hybrid system at any time (mg)

$\mathrm{q}_{\text {DOC }}^{\text {accum,t }}$ : DOC amount accumulated within the hybrid system at any time (mg)

$\mathrm{q}_{\text {DOC }}^{\text {diss,t }}:$ DOC amount dissolved in water $(\mathrm{mg})$

$\mathrm{q}_{\text {DOC }}^{\text {MIEX,t }}$ : DOC amount loaded onto the MIEX resin (mg)

$\mathrm{q}_{\mathrm{Br}}^{\mathrm{MIEX}, \mathrm{t}}: \mathrm{Br}^{-}$amount loaded onto the MIEX resin (mg)

RO: reverse osmosis

UF: ultrafiltration

$\mathrm{V}_{\text {tank }}$ : volume of the tank (L)

\section{ACKNOWLEDGEMENTS}

The authors gratefully acknowledge the personal at the Sant Joan Despí DWTP for their cooperation throughout the study, B. Lefèvre for his helpful assistance with the pilot set-up and OricaWatercare for providing MIEX resin. This study received financial support from the Spanish Ministerio de Economía y Competitividad through the Zero-Discharge (CTQ-201126799) and the Waste2Product (CTM2014-57302-R) projects, and from the Agency for University Grants Administration and Research (AGAUR) of the Catalan Government through the Research Groups Support program (2014-SGR-050). 


\section{REFERENCES}

[1] Y. Yang, Y. Komaki, S.Y. Kimura, H.Y. Hu, E.D. Wagner, B.J. Mariñas, M.J. Plewa, Toxic impact of bromide and iodide on drinking water disinfected with chlorine or chloramines. Environ. Sci. Technol. 48 (2014) 12362-12369.

[2] M. Drikas, M. Dixon, J. Morran, Long term case study of MIEX pre-treatment in drinking water; understanding NOM removal, Water Res. 45 (2011) 1093-1110.

[3] S.E.H.Comstock, T.H. Boyer, Combined magnetic ion exchange and cation exchange for removal of DOC and hardness, Chem. Eng. J. 241 (2014) 366-375.

[4] J.N. Apell, T.H. Boyer, Combined ion exchange treatment for removal of dissolved organic matter and hardness, Water Res. 44 (2010) 2419-2430.

[5] H. Huang, H.H. Cho, K.J. Schwab, J.G. Jacangelo, Effects of magnetic ion exchange pretreatment on low pressure membrane filtration of natural surface water, Water Res. 46 (2012) 5483-5490.

[6] O. Gibert, B. Lefèvre, A. Teuler, X. Bernat, J. Tobella, Distribution of dissolved organic matter fractions along several stages of a drinking water treatment plant, J. Water Process Eng. $6(2015) 64-71$

[7] H. Humbert, H. Gallard, V. Jacquemet, J.P. Croué, Combination of coagulation and ion exchange for the reduction of UF fouling properties of a high DOC content surface water, Water Res. 41 (2007) 3803-3811. 
[8] A.M. Karpinska, R.A.R. Boaventura, V.J.P. Vilar, A. Bilyk, M. Molczan, Applicability of MIEX ${ }^{\circledR D O C}$ process for organics removal from NOM laden water, Environ Sci. Pollut. Res. 20 (2013) 3890-3899.

[9] T.H. Boyer, P.C. Singer, Bench-scale testing of a magnetic ion exchange resin for removal of disinfection by-product precursors, Water Res. 39 (2005) 1265-1276.

[10] H. Humbert, H. Gallard, H. Suty, J.P. Croué, Performance of selected anion exchange resins for the treatment of a high DOC content surface water, Water Res. 39 (2005) 1699-1708.

[11] B. Warton, A. Heitz, L.R. Zappia, P.D. Franzmann, D. Masters, C.A. Joll, M. Alessandrino, B. Allpike, B. O’Leary, R.I. Kagi, Magnetic ion exchange drinking water treatment in a large-scale facility. J. Am. Water Works Ass. 99 (2007) 89-101.

[12] T.H. Boyer, P.C. Singer, A pilot-scale evaluation of magnetic ion exchange treatment for removal of natural organic material and inorganic anions, Wat. Res. 40 (2006) 2865-2876.

[13] S. Hsu, P.C. Singer, Removal of bromide and natural organic matter by anion exchange, Water Res. 44 (2010) 2133-2140.

[14] R. Zhang, S. Vigneswaran, H. H. Ngo, H. Nguyen, Magnetic ion exchange (MIEX®) resin as a pre-treatment to a submerged membrane system in the treatment of biologically treated wastewater, Desalination 192 (2006) 296-302.

[15] Y.H. Choi, J.H. Kweon, Y.M. Jeong, S. Kwon, H.S. Kim, Effects of magnetic ionexchange resin addition during coagulation on floc properties and membrane filtration, Water Environ. Res. 82 (2010) 259-266. 
[16] T. Zeng, C.J. Wilson, W.A. Mitch, Effect of Chemical Oxidation on the Sorption Tendency of Dissolved Organic Matter to a Model Hydrophobic Surface, Environ. Sci. Technol. 48 (2014) $5118-5126$.

[17] M.R.D. Mergen, B. Jefferson, S.A. Parsons, P. Jarvis, Magnetic ion-exchange resin treatment: Impact of water type and resin use, Water Res. 42 (2008) 1977-1988.

[18] A. Phetrak, J. Lohwacharin, H. Sakai, M. Murakami, K. Oguma, S. Takizawa, Simultaneous removal of dissolved organic matter and bromide from drinking water source by anion exchange resins for controlling disinfection by-products, J. Environ. Sci. 26 (2014) 12941300.

[19] Z. Xu, R. Jiao, H. Liu, D. Wang, C.W.K. Chow, M. Drikas, Hybrid treatment process of using MIEX and high performance composite coagulant for DOM and bromide removal, J. Environ. Eng. 139 (2013) 79-85.

[20] K.M. Walker, T.H. Boyer, Long-term performance of bicarbonate-form anion exchange: removal of dissolved organic matter and bromide from the St. Johns River, FL, USA, Water Res. 45 (2011) 2875-2886.

[21] C.J. Johnson, P.C. Singer, Impact of a magnetic exchange resin on ozone demand and bromate formation during drinking water treatment. Water Res. 38 (2004) 3738-3750.

[22] B.P. Allpike, A. Heitz, C.A. Joll, R.I. Kagi, G. Abbt-Braun, F.H. Frimmel, T. Brinkmann, N. Her, G. Amy, Size exclusion chromatography to characterize DOC removal in drinking water treatment, Environ. Sci. Technol. 39 (2005) 2334-2342. 
[23] P.C. Singer, M. Schneider, J. Edwards-Brandt, G.C. Budd, MIEX for removal of DBP precursors: pilot-plant findings. J. Am. Water Works Ass. 94 (2007) 128-139.

[24] T.V. Nguyen, R. Zhang, S. Vigneswaran, H.H. Ngo, J. Kandasamy, P. Mathes, Removal of organic matter from effluents by Magnetic Ion Exchange (MIEX®), Desalination 276 (2011) 96-102.

[25] H.C. Kim, B.A. Dempsey, Removal of organic acids from EfOM using anion exchange resins and consequent reduction of fouling in UF and MF, J. Membr. Sci. 364 (2010) 325-330.

[26] S.A. Huber, A. Balz, M. Abert, W. Pronk, Characterisation of aquatic humic and nonhumic matter with size-exclusion chromatography - organic carbon detection - organic nitrogen detection (LC-OCD-OND), Water Res. 45 (2011) 879-885.

[27] W. Chen, P. Westerhoff, J.A. Leenheer, K. Booksh, Fluorescence excitation -emission matrix regional integration to quantify spectra for dissolved organic matter, Environ. Sci. Technol. 37 (2003) 5701-5710.

[28] N. Ates, F.B. Incetan, Competition impact of sulfate on NOM removal by anion-exchange resins in high-sulfate and low-SUVA waters, Ind. Eng. Chem. Res. 52 (2013) 14261-14269.

[29] X. Zhang, F. Li, X.Zhao, Application of a magnetic resin (MIEX®) in wastewater reclamation for managed aquifer recharge, Water Air Soil Pollut. 223 (2012) 4687-4694.

[30] R.K. Henderson, N. Subhi, A. Antony, S.J. Khan, K.R. Murphy, G.L. Leslie, V. Chen, R.M. Stuetz, P. Le-Clech, Evaluation of effluent organic matter fouling in ultrafiltration treatment using advanced organic characterisation techniques, J. Membr. Sci. 382 (2011) 50-59. 